\title{
Reaction Rate between Alumina Graphite Immersion Nozzle and Low Carbon Steel
}

\author{
Katsuhiro SASAI and Yoshimasa MIZUKAMI
}

Nagoya R \& D Laboratories, Nippon Steel Corporation, Tokai-machi, Tokai, Aichi-ken, 476 Japan.

(Received on July 21, 1994; accepted in final form on September 16, 1994)

\begin{abstract}
A kinetic study has been made on the reaction between a silica-containing alumina graphite refractory and low carbon molten steel by measuring mass loss of the refractory heated at $1100-1600^{\circ} \mathrm{C}$ and $\mathrm{Si}$ content of the molten steel at $1600^{\circ} \mathrm{C}$ where the refractory was immersed.

The results are summarized as follows:

(1) The reaction in the refractory is controlled by the diffusion of SiO gas and $\mathrm{CO}$ gas through the pores in the refractory.

(2) The rate of reaction between the refractory and the molten steel is controlled by diffusion of the $\mathrm{SiO}$ gas and $\mathrm{CO}$ gas through the pores of oxide film formed at the refractory-molten steel interface.

(3) The rate of the reaction between the refractory and the molten steel is faster in the Ti-killed molten steel than in the Al-killed molten steel and exhibits steel grade dependence. This steel grade dependence can be ascribed to the differences in the gas permeability through the oxide film formed at the refractory-molten steel interface between the Al-killed molten steel and the Ti-killed molten steel.
\end{abstract}

KEY WORDS: refractory; alumina graphite; immersion nozzle; carbothermic reduction; silica; gas diffusion through the pores; gas permeability through the oxide film.

\section{Introduction}

The authors in their previous report ${ }^{1)}$ clarified the reaction mechanism between a silica-containing alumina graphite immersion nozzle and low carbon molten steel from the standpoint of equilibrium theory. The research process recognized the tendency for the reaction rate between the immersion nozzle refractory and Ti-killed molten steel to become faster than that between the immersion nozzle refractory and Al-killed molten steel. Clarification of the mechanism of this steel grade dependence calls for a further study from a kinetics point of view.

To make clearer the reaction mechanism between the refractory and the low carbon molten steel, this study measured the rate of gas formation reaction in the refractory and the rate of reaction between the refractory and the molten steel, compared the two sets of reaction rates, and investigated for a mechanism controlling the overall reaction between the refractory and the molten steel.

\section{Experimental Methods}

\subsection{Refractory Heating Experiment}

Two types of alumina graphite refractories listed in Table 1 were machined into 10 by 10 by $120 \mathrm{~mm}$ shapes and used in the experimental work. Each refractory was suspended above the soaking zone of a Tammann furnace and preheated at $1000^{\circ} \mathrm{C}$ for $20 \mathrm{~min}$. As described later, no mass loss and porosity increase occurred at the preheating temperature. The refractory was lowered into the soaking zone of the furnace and subjected to a heating experiment. The refractory was heated for the specified length of time, cooled above the soaking zone, and removed out of the furnace. The experimental temperature was changed over the range of 1100 to $1600^{\circ} \mathrm{C}$. The Tammann furnace was held under an argon atmosphere to prevent the air oxidation of graphite in the refactory. The weight of each refractory was measured before and after the heating experiment and was used to determine the mass loss of the refractory. Specimens of $10-\mathrm{mm}$ cubic size were machined from the refractory before and after the heating experiment and were tested for apparent porosity according to JIS method (JIS R 2205). The structure of the refractory was observed by optical microscopy before and after the heating experiment.

Table 1. Compositions and properties of refractories used in experiments.

\begin{tabular}{|c|c|c|c|c|c|}
\hline \multirow{2}{*}{ Type } & \multicolumn{3}{|c|}{ Chemical compositions (mass \%) } & \multirow{2}{*}{$\begin{array}{c}\text { Apparent } \\
\text { porosity } \\
(\%)\end{array}$} & \multirow{2}{*}{$\begin{array}{c}\text { Bulk } \\
\text { density } \\
\left(\mathrm{g} / \mathrm{cm}^{2}\right)\end{array}$} \\
\hline & $\mathrm{C}$ & $\mathrm{SiO}_{2}$ & $\mathrm{Al}_{2} \mathrm{O}_{3}$ & & \\
\hline A & 23 & 16 & 61 & 20.4 & 2.40 \\
\hline B & 23 & 30 & 47 & 18.3 & 2.29 \\
\hline
\end{tabular}




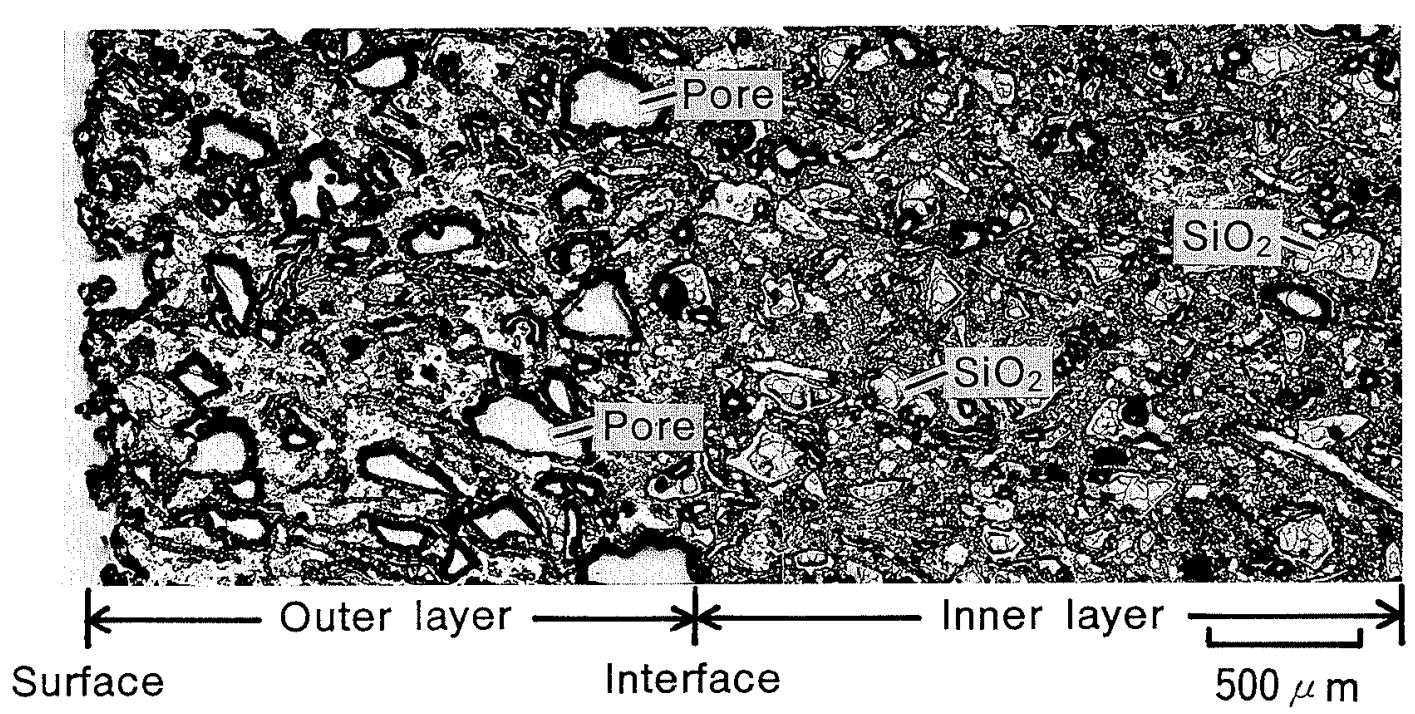

Fig. 1. Microstructure of Type B refractory heated at $1600^{\circ} \mathrm{C}$ for $1 \mathrm{~h}$.

\subsection{Refractory Immersion Experiment}

The Tammann furnace was used as in the heating experiments, and $500 \mathrm{~g}$ of electrolytic iron was charged into an alumina crucible, measuring $40 \mathrm{~mm}$ inside diameter by $50 \mathrm{~mm}$ outside diameter and $150 \mathrm{~mm}$ high, and melted in an argon atmosphere. The composition of the molten steel was adjusted by adding the desired amount of $\mathrm{Al}$ or $\mathrm{Ti}$, and a refractory preheated by the same method as described for the heating experiment was immersed by $6 \mathrm{~cm}$ in the molten steel. Samples of the molten steel were taken by a quartz tube at specified time intervals and analyzed for $\underline{\mathrm{Al}}, \mathrm{Ti}, \underline{\mathrm{Si}}$, and $\underline{\mathrm{C}}$. The molten steel temperature was held constant at $1600^{\circ} \mathrm{C}$, and the initial $\underline{\mathrm{Al}}$ and $\mathrm{Ti}$ contents were changed over the range of 0.03 to 0.20 mass $\%$. Some immersion experiments were run at a higher- $\underline{C}$ level. The refractory after the experiment was cut in the cross section, and the microstructural details and surface buildups of the refractory were observed by light microscopy. Characteristic portions of the refractory were also analyzed by an electron probe microanalyzer (EPMA).

\section{Experimental Results}

\subsection{Reaction Mechanism in Heating Experiment}

Figure 1 shows the optical microstructure of the cross section of the Type B refractory after the heating experiment. The cross section of the refractory consists of two layers. The inner layer has $\mathrm{SiO}_{2}$ with flaky cracks. In the outer layer, there is little or no $\mathrm{SiO}_{2}$, and many pores are formed. This is because $\mathrm{SiO}_{2}$ in the refractory is reduced by $\mathrm{C}$ to form the $\mathrm{SiO}$ gas and $\mathrm{CO}$ gas according to Eq. (1) as described in the previous report. ${ }^{1)}$

$$
\mathrm{SiO}_{2}(\mathrm{~s})+\mathrm{C}(\mathrm{s})=\mathrm{SiO}(\mathrm{g})+\mathrm{CO}(\mathrm{g})
$$

The change with time in the mass loss $\Delta W(\mathrm{~g})$ of the refractories is shown in Fig. 2. The mass loss starts at $1200^{\circ} \mathrm{C}$, and the rate of the mass loss increases with increasing temperature. This means that the reaction of Eq. (1) proceeds to the right side at $1200^{\circ} \mathrm{C}$ and above. Miller $^{2)}$ and $\mathrm{Kyoda}^{3)}$ report that the decomposition of

\begin{tabular}{|c|c|c|c|c|c|c|}
\hline Type & \multicolumn{5}{|c|}{ Temperature ("C) } \\
& 1100 & 1200 & 1300 & 1400 & 1500 & 1600 \\
\hline A & & & & & $\square$ & $\square$ \\
\hline B & 0 & 0 & 0 & $\bullet$ & $\bullet$ & $\bullet$ \\
\hline
\end{tabular}

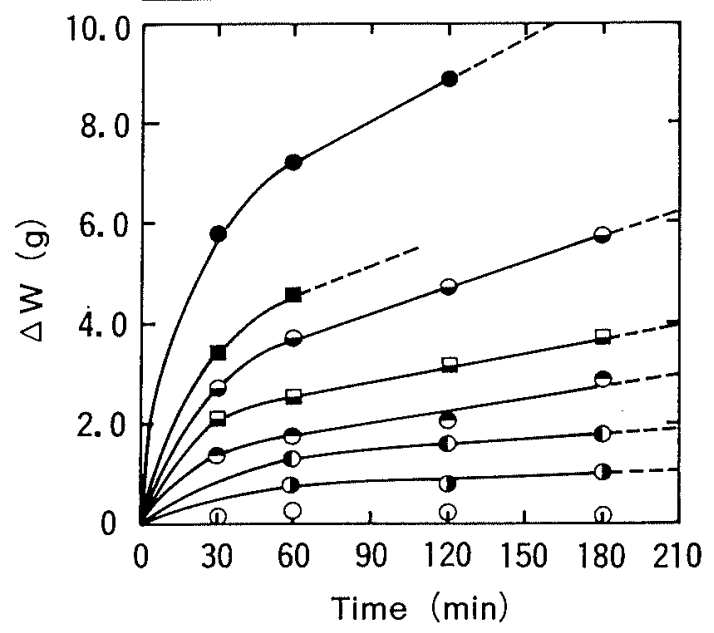

Fig. 2. Changes with time in mass loss of heated refractories.

$\mathrm{SiO}_{2}$ proceeds at $1300^{\circ} \mathrm{C}$ and above. Their finding approximately agrees with this experimental result.

Figure 3 shows the relationship between the mass loss and apparent porosity increase $\Delta \varepsilon(-)$ of the refractories. The porosity increases for the volume of $\mathrm{SiO}_{2}$ and $\mathrm{C}$ lost by the reaction of Eq. (1). In this case, the relationship of Eq. (2) holds between the mass loss and porosity increase of the refractory.

$$
\Delta \varepsilon=\Delta W \cdot\left(M_{\mathrm{SiO}_{2}} / \rho_{\mathrm{SiO}_{2}}+M_{\mathrm{C}} / \rho_{\mathrm{C}}\right) /\left\{\left(M_{\mathrm{SiO}_{2}}+M_{\mathrm{C}}\right) \cdot V\right\}
$$

where $M$ is the molecular weight; $\rho$ is density $\left(\mathrm{g} / \mathrm{cm}^{3}\right)$; $V$ is the volume of the refractory $\left(\mathrm{cm}^{3}\right)$; the subscript $\mathrm{SiO}_{2}$ indicates silica; and the subscript $\mathrm{C}$ indicates carbon. The relationship between the mass loss and porosity increase obtained by this experimental work agrees well with Eq. (2). This also means that the mass loss and porosity increase of the refractory are attributable to the reaction of Eq. (1). 


\begin{tabular}{|c|c|c|c|c|c|}
\hline Type & \multicolumn{5}{|c|}{ Temperature ('C) } \\
& 1200 & 1300 & 1400 & 1500 & 1600 \\
\hline A & & & & $\square$ & $\square$ \\
\hline B & 0 & $\mathbf{D}$ & $\bullet$ & $\bullet$ & $\bullet$ \\
\hline
\end{tabular}

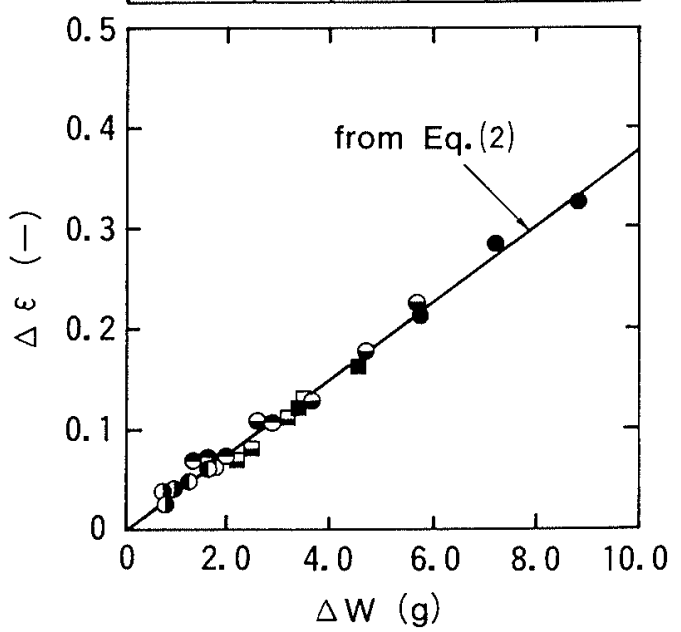

Fig. 3. Relationship between mass loss and apparent porosity increase of heated refractories.

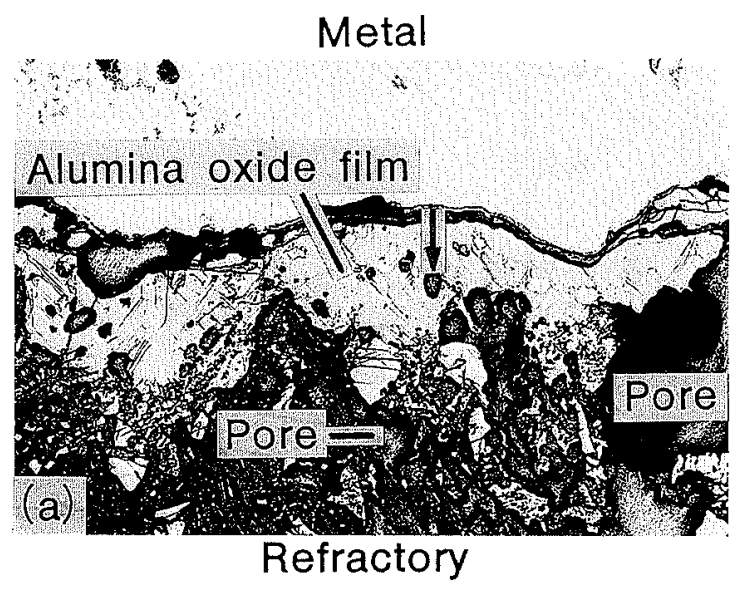

\subsection{Reaction Mechanism in Immersion Experiment}

Figure 4 shows the micrographs of the surfaces of the refractories immersed in Al-killed molten steel and Tikilled molten steel. Also in the immersion experiment, $\mathrm{SiO}_{2}$ in the outer layer of the refractory is lost, and many pores are formed. The refractory-molten steel interface reveals an alumina oxide film for the Al-killed molten steel and a titania oxide film for the Ti-killed molten steel.

Figure 5 shows the changes with time in the $\underline{\mathrm{C}}, \underline{\mathrm{Si}}, \underline{\mathrm{Al}}$, and Ti contents of the Al-killed molten steel and Ti-killed molten steel in the refractory immersion experiments. The Al-killed molten steel increases in the $\mathrm{C}$ and $\mathrm{Si}$ contents and decreases in the $\mathrm{Al}$ content with time. The Ti-killed molten steel shows almost the same tendencies as the Al-killed molten steel, but is different from the Al-killed molten steel in that the rise in the $\underline{C}$ content is arrested in the middle of the experiment.

The above results may be explained as follows. As described in the previous report, ${ }^{1)}$ the reduction of $\mathrm{SiO}_{2}$ by $\mathrm{C}$ according to the reaction of $\mathrm{Eq}$. (1) forms the $\mathrm{SiO}$ gas and $\mathrm{CO}$ gas. These gases diffuse through the pores

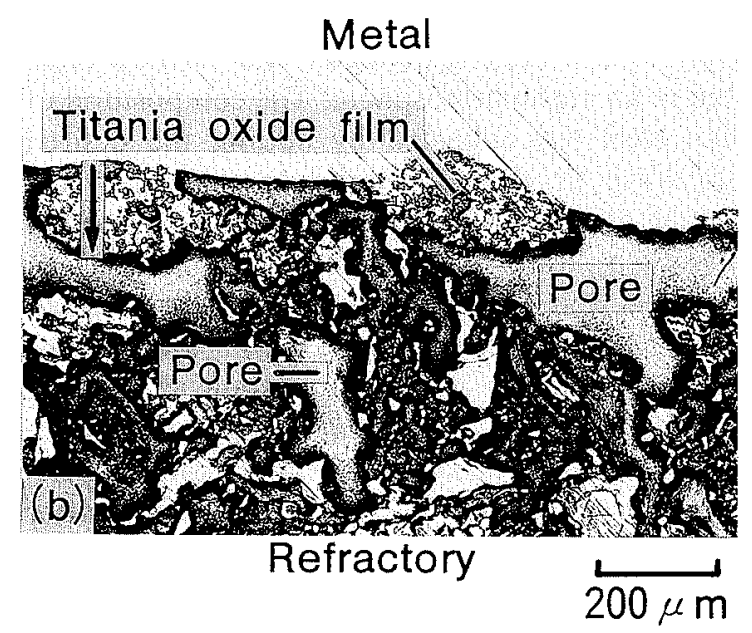

Fig. 4. Micrographs of the refractory-Al killed molten steel interface and refractory-Ti killed molten steel interface.

(a) 0.03 mass $\%$ Al-killed molten steel

(b) 0.2 mass $\%$ Ti-killed molten steel
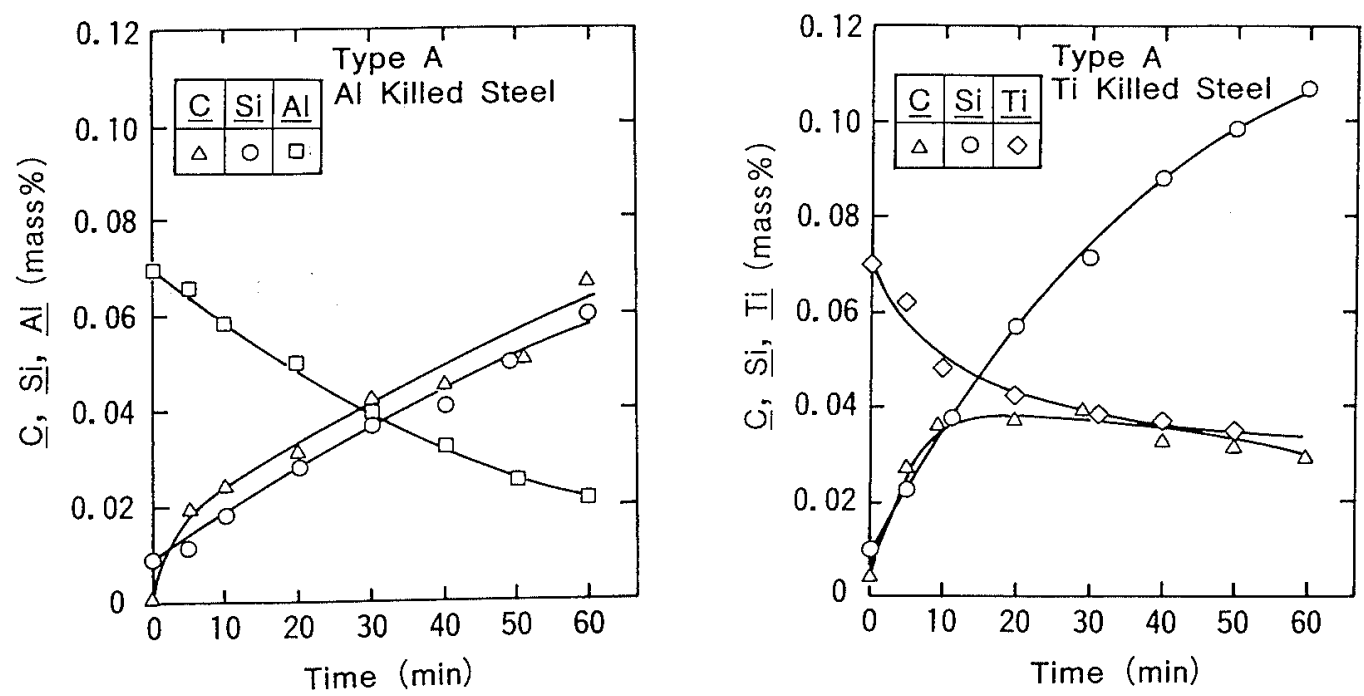

Fig. 5. Changes with time in $\underline{\mathrm{C}}, \underline{\mathrm{Si}}, \underline{\mathrm{Al}}$, and $\underline{\mathrm{Ti}}$ contents of molten steel into which refractory was immersed. 
in the refractory and react with the $\mathrm{Al}$ or $\mathrm{Ti}$ in the molten steel at the refractory-molten steel interface as expressed by the following equations:

$$
\begin{aligned}
& 3 \mathrm{SiO}(\mathrm{g})+2 \underline{\mathrm{Al}}=\mathrm{Al}_{2} \mathrm{O}_{3}(\mathrm{~s})+3 \underline{\mathrm{Si}} \\
& 3 \mathrm{CO}(\mathrm{g})+2 \underline{\mathrm{Al}}=\mathrm{Al}_{2} \mathrm{O}_{3}(\mathrm{~s})+3 \underline{\mathrm{C}} \\
& 5 \mathrm{SiO}(\mathrm{g})+3 \underline{\mathrm{Ti}}=\mathrm{Ti}_{3} \mathrm{O}_{5}(\mathrm{~s})+5 \underline{\mathrm{Si}} \\
& 5 \mathrm{CO}(\mathrm{g})+3 \underline{\mathrm{Ti}}=\mathrm{Ti}_{3} \mathrm{O}_{5}(\mathrm{~s})+5 \underline{\mathrm{C}}
\end{aligned}
$$

In this case, the reaction between the refractory and the Al-killed molten steel follows the overall reaction of Eq. (7), and the reaction between the refractory and the Ti-killed molten steel follows the overall reaction of Eq. (8) or (9).

$$
\begin{aligned}
& 3 \mathrm{SiO}_{2}(\mathrm{~s})+3 \mathrm{C}(\mathrm{s})+4 \underline{\mathrm{Al}}=2 \mathrm{Al}_{2} \mathrm{O}_{3}(\mathrm{~s})+3 \underline{\mathrm{Si}}+3 \underline{\mathrm{C}} \ldots \ldots \\
& 5 \mathrm{SiO}_{2}(\mathrm{~s})+5 \mathrm{C}(\mathrm{s})+6 \underline{\mathrm{Ti}}=2 \mathrm{Ti}_{3} \mathrm{O}_{5}(\mathrm{~s})+5 \underline{\mathrm{Si}}+5 \underline{\mathrm{C}} \ldots \ldots . . \\
& 5 \mathrm{SiO}_{2}(\mathrm{~s})+5 \mathrm{C}(\mathrm{s})+3 \underline{\mathrm{Ti}}=\mathrm{Ti}_{3} \mathrm{O}_{5}(\mathrm{~s})+5 \underline{\mathrm{Si}}+5 \mathrm{CO}(\mathrm{g})
\end{aligned}
$$

In the immersion experiment, graphite in the surface layer of the refractory is directly dissolved in the molten steel in the first half of the experiment. As the $\underline{C}$ content increases accordingly, part of the $\mathrm{SiO}$ gas reacts with the $\underline{C}$ in the molten steel in the last half of the experiment when the Ti content falls. Strictly speaking, these changes in the chemical composition of the molten steel do not satisfy the mass balance represented by each equation. When the mass balance is studied by considering that the sharp increase in the $\mathrm{C}$ content in the first $10 \mathrm{~min}$ of the experiment arises from the direct dissolution of graphite and that the drop in the $\underline{C}$ content after $40 \mathrm{~min}$ of the experiment arises from the reaction of the $\mathrm{SiO}$ gas and the $\mathrm{C}$ in the molten steel, the reaction of Eq. (7) is mainly considered to occur between the refractory and the Al-killed molten steel, and the reaction of Eq. (9) where the $\underline{C}$ content does not rise is mainly considered to occur between the refractory and the Ti-killed molten steel.

\section{Discussion}

The reaction between the refractory and the molten steel can be studied by dividing it into the reaction in the refractory and the reaction of the interface between the refractory and the molten steel. Each reaction consists of the following elementary processes:

(1) Reaction in refractory

a) Reduction of $\mathrm{SiO}_{2}$ by $\mathrm{C}$ as expressed by Eq. (1)

b) Diffusion of $\mathrm{SiO}$ gas and $\mathrm{CO}$ gas through pores in refractory

(2) Reaction of refractory-molten steel interface

c) Diffusion of $\mathrm{SiO}$ gas and $\mathrm{CO}$ gas through pores of oxide film at refractory-molten steel interface

d) Transfer of $\underline{\mathrm{Al}}$ and $\mathrm{Ti}$ from molten steel to refractory-molten steel interface

e) Chemical reactions of refractory-molten steel interface as expressed by Eqs. (3) to (6)

f) Transfer of $\underline{\mathrm{C}}$ and $\underline{\mathrm{Si}}$ from refractory-molten steel interface to molten steel

The slowest of the above elementary processes controls the overall reaction between the refractory and the molten steel. The process that controls the reaction in the refractory is studied, based on the results of the heating experiment, and the reaction rates in the heating experiment and immersion experiment are compared to identify the process that controls the overall reaction between the refractory and the molten steel.

\subsection{Study of Process Controlling Reaction in Refrac- tory}

4.1.1. Derivation of Rate Equations for Control of Reaction in Refractory by Chemical Reaction

The reduction of $\mathrm{SiO}_{2}$ by $\mathrm{C}$ increases the porosity of the reacted zone in the refractories studied here and favors topochemical reaction. ${ }^{4)}$ As evident from Fig. 1, pores are partly formed in $\mathrm{SiO}_{2}$ in the inner layer, but the topochemical reaction is assumed to proceed on the whole. A reaction interface that moves in a concentric circuit pattern is assumed, and rate equations are derived as described below.

The weight of the refractory is reduced by the reaction of Eq. (1), so that the mass loss is given by Eq. (10).

$$
\Delta W=\pi \cdot l \cdot \gamma \cdot A_{\mathrm{SiO}_{2}} \cdot\left(r_{0}^{2}-r_{i}^{2}\right) \cdot\left(1+M_{\mathrm{C}} / M_{\mathrm{SiO}_{2}}\right)
$$

where $r_{0}$ is the radius of the refractory $(\mathrm{cm}) ; r_{i}$ is the radius of the reaction interface $(\mathrm{cm}) ; l$ is the length of the refractory $(\mathrm{cm}) ; \gamma$ is the bulk density of the refractory; and $A_{\mathrm{SiO}_{2}}$ is the $\mathrm{SiO}_{2}$ content of the refractory ( - ).

When the rate of reaction in the refractory is controlled by the chemical reaction, or process a) mentioned above, the rate of the mass loss of the refractory is given by

$$
\begin{aligned}
d \Delta W / d t= & 2 \pi \cdot r_{i} \cdot l \cdot k \cdot\left(a_{\mathrm{SiO}_{2}} \cdot a_{\mathrm{C}}-p_{\mathrm{SiO}} \cdot p_{\mathrm{Co}} / K\right) \\
& \times\left(M_{\mathrm{SiO}_{2}}+M_{\mathrm{C}}\right) \ldots \ldots \ldots \ldots \ldots \ldots \ldots \ldots \ldots \ldots \ldots \ldots \ldots \ldots \ldots \ldots
\end{aligned}
$$

where $t$ is time (s); $k$ is the rightward rate constant of Eq. (1) at the reaction interface $\left(\mathrm{mol} \cdot \mathrm{cm}^{-2} \cdot \mathrm{s}^{-1}\right) ; a$ is activity; $p$ is gas partial pressure (atm); and $K$ is the equilibrium constant of Eq. (1). Solving the differential equation of Eq. (11) by using Eq. (10) yields Eq. (12).

$$
1-(1-\alpha)^{0.5}=k_{R} \cdot t
$$

where $k_{R}(1 / \mathrm{s})$ is given by

$$
k_{R}=\pi \cdot r_{0} \cdot l \cdot k \cdot\left(a_{\mathrm{SiO}_{2}} \cdot a_{\mathrm{C}}-p_{\mathrm{SiO}} \cdot p_{\mathrm{Co}} / K\right)\left(M_{\mathrm{SiO}_{2}}+M_{\mathrm{C}}\right) / \Delta W_{\mathrm{O}}
$$

where $\alpha$ is the fractional conversion (-); and $\Delta W_{0}$ is the mass loss resulting when all of $\mathrm{SiO}_{2}$ in the refractory reacts $(\mathrm{g})$. The fractional conversion and the mass loss are respectively given by

$$
\begin{aligned}
& \alpha=\Delta W / \Delta W_{0} \\
& \Delta W_{0}=\pi \cdot r_{0}^{2} \cdot l \cdot \gamma \cdot A_{\mathrm{SiO}_{2}} \cdot\left(1+M_{\mathrm{C}} / M_{\mathrm{SiO}_{2}}\right)
\end{aligned}
$$

If the measured values satisfy Eq. (12), therefore, a linear relation can hold between $1-(1-\alpha)^{0.5}$ and $t$, and the reaction in the refractory is controlled by the chemical reaction.

4.1.2. Derivation of Rate Equations for Control of Reaction in Refractory by Diffusion

When the reaction in the refractory is controlled by the diffusion of gases through the pores in the refractory, or the process $b$ ) mentioned above, the rate of the mass 
loss of the refractory in an assumed steady state is given by

$$
\begin{aligned}
d \Delta W / d t= & -2 \pi \cdot l \cdot\left(M_{\mathrm{SiO}} \cdot D_{\mathrm{eff}, \mathrm{SiO}} \cdot C_{\mathrm{SiO}}\right. \\
& \left.+M_{\mathrm{Co}} \cdot D_{\mathrm{eff}, \mathrm{CO}} \cdot C_{\mathrm{CO}}\right) / \ln \left(r_{i} / r_{0}\right)
\end{aligned}
$$

where $D_{\text {eff }}$ is the diffusion coefficient for the gases through the pores $\left(\mathrm{cm}^{2} / \mathrm{s}\right)$; and $C_{\mathrm{SiO}}$ and $C_{\mathrm{CO}}$ are the $\mathrm{SiO}$ gas and $\mathrm{CO}$ gas concentrations at the reaction interface $\left(\mathrm{mol} / \mathrm{cm}^{3}\right)$. Since the gas species are not considered to have an appreciable influence on the diffusion coefficient for the gases through the pores, $D_{\text {eff,sio }}=D_{\text {eff,co }}$. Solving the differential equation of Eq. (16) by using the stoichiometric relation $C_{\mathrm{SiO}}=C_{\mathrm{Co}}$ of Eq. (1) and Eq. (10) yields Eq. (17).

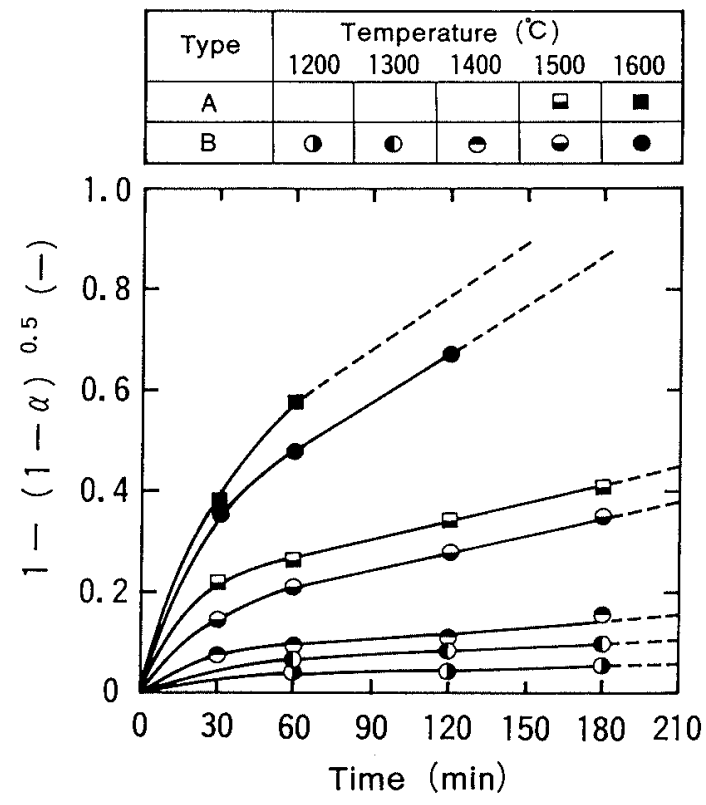

Fig. 6. Relationship between $1-(1-\alpha)^{0.5}$ and time $(\alpha=$ fractional conversion).

\begin{tabular}{|c|c|c|c|c|c|}
\hline \multirow{2}{*}{ Type } & \multicolumn{5}{|c|}{ Temperature ("C) } \\
& 1200 & 1300 & 1400 & 1500 & 1600 \\
\hline A & & & & $\bullet$ & $\square$ \\
\hline B & 0 & 0 & 0 & 0 & $\bullet$ \\
\hline
\end{tabular}

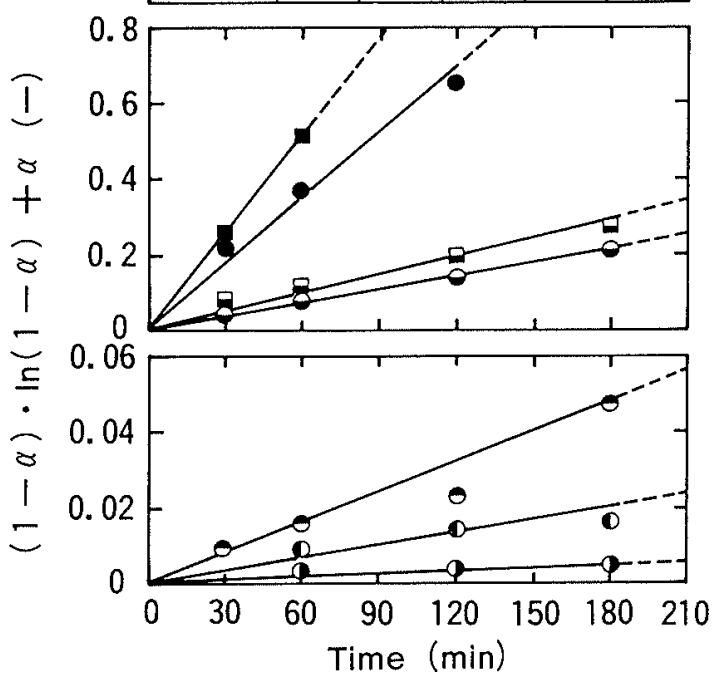

Fig. 7. Relationship between $(1-\alpha) \cdot \ln (1-\alpha)+\alpha$ and time $(\alpha=$ fractional conversion).

$$
(1-\alpha) \cdot \ln (1-\alpha)+\alpha=k_{D} \cdot t
$$

where $k_{D}(1 / \mathrm{s})$ is given by

$$
k_{D}=4 \pi \cdot l \cdot D_{\text {eff,Co }} \cdot C_{\mathrm{Co}} \cdot\left(M_{\mathrm{SiO}_{2}}+M_{\mathrm{C}}\right) / \Delta W_{0}
$$

If the reaction rate in the refractory is controlled by the diffusion of the gases through the pores in the refractory, therefore, the measured values can satisfy Eq. (17), and a linear relation can hold between $(1-\alpha)$. $\ln (1-\alpha)+\alpha$ and $t$.

\subsubsection{Application of Rate Equations to Measured Values}

Figures 6 and 7 show the results of the heating experiments of the refractories according to Eqs. (12) and (17). A linear relationship does not hold in Fig. 6 where the experimental results are arranged by assuming that the reaction in the refractory is controlled by the chemical reaction as expressed by Eq. (12). A good linear relationship holds in Fig. 7 where the experimental results are arranged by assuming that the reaction in the refractory is controlled by the diffusion of the gases through the pores in the refractory. It is thus obvious that the rate of reaction in the refractory is controlled by the diffusion of the $\mathrm{SiO}$ gas and $\mathrm{CO}$ gas through the pores in the refractory.

The rate constant $k_{D}$ for the control of the reaction in the refractory by the diffusion of the gases through the pores in the refractory is calculated from the slope of the straight lines in Fig. 7 and is represented as an Arrhenius plot as shown in Fig. 8. For the Type B refractory, a practically linear relationship holds between $k_{D}$ and a reciprocal number of absolute temperature $T^{-1}$, and the activation energy is calculated to be $345 \mathrm{~kJ} / \mathrm{mol}$. Since the reactions in the Type $A$ and $B$ refractories are controlled by the same mechanism according to Fig. 7, they are considered to agree in activation energy as well. This value of activation energy is large for the control of the reaction in the refractory by the diffusion of the gases through the pores in the refractory, but $k_{D}$ includes

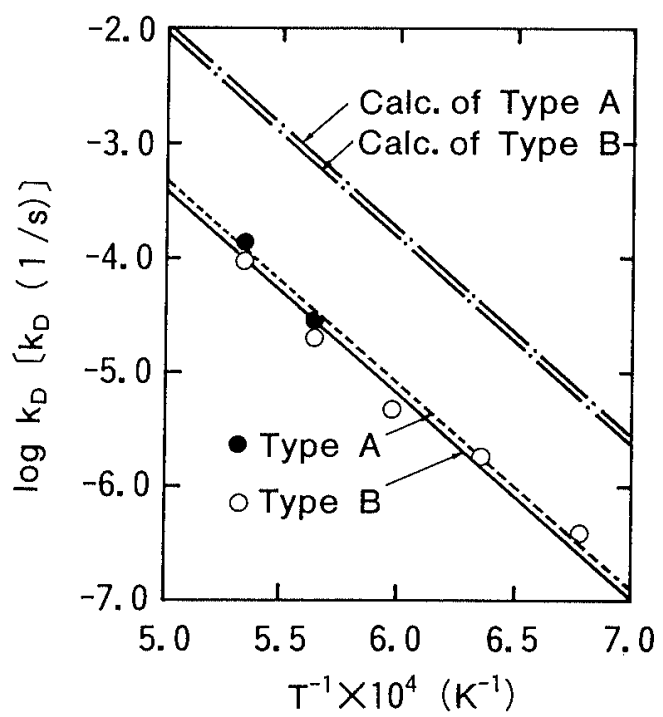

Fig. 8. Comparison between calculated values and observed values of $k_{D}\left(k_{D}=\right.$ rate constant for control of reaction rate by diffusion of gases through pores in refractory). 
the temperature dependence of $C_{\mathrm{Co}}$ as evident from Eq. (18).

4.1.4. Estimation of Rate Constant for Control of Reaction in Refractory by Diffusion of Gases through Pores

The diffusion coefficient for the gases through the pores in the refractory is given by

$$
D_{\text {eff }}=D \cdot \varepsilon \cdot \xi
$$

where $D$ is the diffusion coefficient for gas in free space $\left(\mathrm{cm}^{2} / \mathrm{s}\right) ; \varepsilon$ is porosity $(-) ; \xi$ is the tortuosity factor $(-)$. The tortuosity factor indicates resistance to the diffusion of gases through pores and is theoretically given by ${ }^{5)}$

$$
\xi=\varepsilon^{0.5}
$$

The diffusion coefficient for gas in free space can be estimated from the equation of Bird et al. ${ }^{6)}$ If $\varepsilon$ is known, therefore, $D_{\text {eff }}$ can be obtained. When the reaction proceeds topochemically, the porosity of the gas diffusion layer is the porosity of the refractory after the reaction of all of $\mathrm{SiO}_{2}$ and is calculated by Eqs. (2) and (15) to be $41.2 \%$ for the Type A refractory and $55.6 \%$ for the Type $\mathrm{B}$ refractory.

When the rate of reaction in the refractory is controlled by the diffusion of gases through the pores in the refractory, the chemical reaction of Eq. (1) at the reaction interface is in equilibrium. If the stoichiometric relations $C_{\mathrm{SiO}}=C_{\mathrm{Co}}$ and $a_{\mathrm{C}}=1$ hold, the $\mathrm{CO}$ gas concentration at the reaction interface is given by

$$
C_{\mathrm{CO}}=a_{\mathrm{SiO}_{2}}^{0.5} \cdot \exp \left\{-\Delta G^{\circ} /(2 R T)\right\} /\left(R^{\prime} \cdot T\right)
$$

where $R\left(\mathrm{~J} \cdot \mathrm{mol}^{-1} \cdot \mathrm{K}^{-1}\right)$ and $R^{\prime}\left(\mathrm{atm} \cdot \mathrm{cm}^{3} \cdot \mathrm{mol}^{-1} \cdot \mathrm{K}^{-1}\right)$ are both gas constants. $C_{\text {Co }}$ can be thus estimated from the change $\Delta G^{\circ}(\mathrm{J} / \mathrm{mol})^{7)}$ in the standard free energy of formation for the reaction of Eq. (1) and the activity of $\mathrm{SiO}_{2} a_{\mathrm{SiO}_{2}}$.

The above-mentioned results show that $k_{D}$ can be found by substituting Eqs. (19) to (21) into Eq. (18). The dot-dash lines in Fig. 8 are the values of $k_{D}$ calculated for the Type $A$ and $B$ refractories and presented on an Arrhenius plot. The activity of $\mathrm{SiO}_{2}$ is assumed to be 1.0. The calculated values are greater by about one order of magnitude than the observed values, but the slopes of the straight lines indicating the calculated values are the same as those of the straight lines indicating the observed values. The calculated values of activation energy for $k_{D}$ agree with the theoretical values. The absolute values of $k_{D}$ are different, probably because some of $\mathrm{SiO}_{2}$ remains in the gas diffusion layer and the porosity is smaller than when all of $\mathrm{SiO}_{2}$ is reacted, and because the activity of $\mathrm{SiO}_{2}$ is reduced when the refractory contains $\mathrm{Al}_{2} \mathrm{O}_{3}$. ${ }^{1}$ )

\subsection{Study of Process Controlling Overall Reaction between Refractory and Molten Steel}

Figure 9 shows the change with time in the $\underline{\mathrm{Si}}$ content increase $\Delta \underline{\mathrm{Si}}$ (mass\%) in the molten steel. Since the $\underline{\mathrm{C}}$ content increase and the $\mathrm{Al}$ content increase appear to have no effect on the $\underline{\mathrm{Si}}$ content increase in the molten steel, it is difficult to think that the process d) or f)

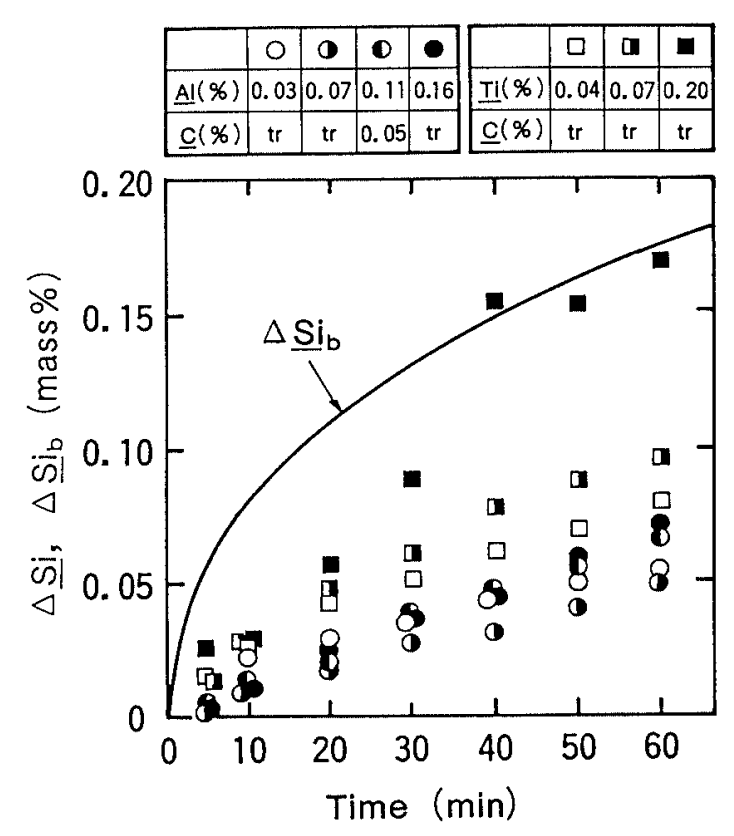

Fig. 9. Comparison between observed increase in $\underline{\mathrm{Si}}$ content of molten steel and increase in $\underline{\mathrm{Si}}$ content of low carbon molten steel calculated by diffusion model for gases through pores in refactory.

controls the overall reaction between the refractory and the molten steel. Since chemical reaction at high temperatures is generally considered to rapidly proceed, the process e) can also be excluded as a controlling process. Judging from the result of the heating experiment, it is impossible for the process a) to control the overall reaction between the refractory and the molten steel. This leaves the process b) or c) as the process that controls the overall reaction between the refractory and the molten steel.

If the overall reaction between the refractory and the molten steel is controlled by the process $b$ ), the fractional conversion of the refractory can be calculated by Eq. (17). If the $\mathrm{SiO}$ gas and $\mathrm{CO}$ gas generated by the refractory immersed in the molten steel are absorbed by the molten steel, the $\underline{\mathrm{Si}}$ content increase $\Delta \underline{\mathrm{Si}}_{\mathrm{b}}$ (mass\%) in the molten steel when the process $b$ ) is the controlling process is given by

$$
\Delta \underline{\mathrm{Si}}_{\mathrm{b}}=100 \cdot \alpha \cdot \Delta W_{0} \cdot h \cdot M_{\mathrm{Si}} /\left\{\left(M_{\mathrm{SiO}_{2}}+M_{\mathrm{C}}\right) \cdot W_{\mathrm{S}} \cdot l\right\}
$$

where $W_{\mathrm{S}}$ is the amount of the molten steel $(\mathrm{g})$ in the immersion experiment; and $h$ is the immersion depth of the refractory in the molten steel. $\Delta \underline{S i}_{b}$ is calculated from $k_{D}$ derived in the heating experiment and is shown in Fig. 9. As evident from Fig. 9, $\Delta \underline{\mathrm{Si}} \leqq \Delta \underline{\mathrm{Si}}_{\mathrm{b}}$, and the rate of the reaction between the refractory and the molten steel is lower than that when the process b) is a ratecontrolling process. It is thus considered that the reaction between the refractory and the molten steel is more strongly influenced by the process $\mathrm{c}$ ), or the diffusion of the $\mathrm{SiO}$ gas and $\mathrm{CO}$ gas through the pores of oxide film at the refractory-molten steel interface, than the process b).

\subsection{Study of Steel Grade Dependence}

It is clear from Fig. 9 that the Si content increase is 

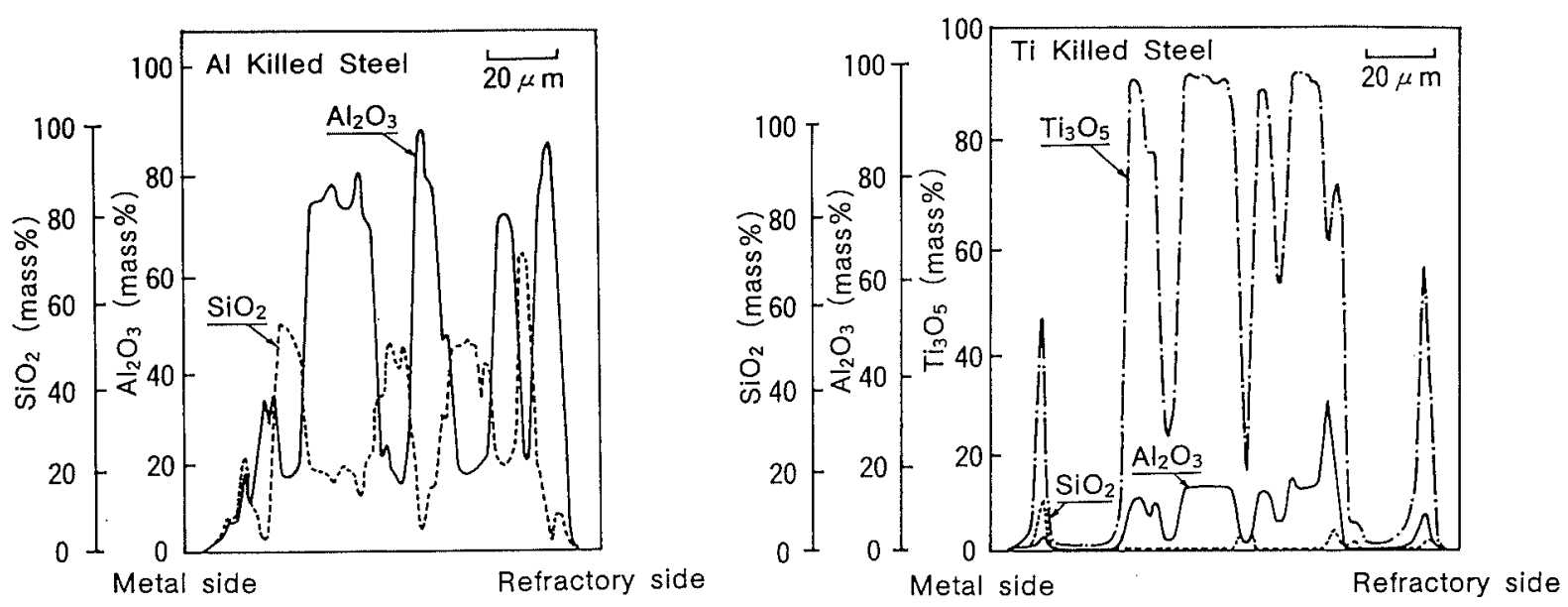

Fig. 10. Results of EPMA line analysis of oxide film formed on surface of refractories immersed in Al-killed molten steel and Ti-killed molten steel.

greater in the Ti-killed molten steel than in the Al-killed molten steel and that the rate of the reaction between the refractory and the molten steel depends on the steel grade. This supports the fact that the rate of the reaction between the refractory and the molten steel is mainly controlled by the process c) as already described. The steel grade dependence is attributable to the difference in the nature of the oxide film.

When the oxide film at the refractory-molten steel interface is observed in detail, it is found that the refractory is nearly covered with a relative dense oxide film for the Al-killed molten steel. For the Ti-killed molten steel, in contrast, the refractory is discontinuously covered with a relative porous oxide film, and the greater the percentage of the refractory surface exposed, the greater the $\underline{\mathrm{Si}}$ content increase in the molten steel.

Figure 10 shows the results of EPMA line analysis of the oxide films (indicated by the arrows in Fig. 4) formed on the surface of the refractory immersed in the Al-killed molten steel and Ti-killed molten steel. The oxide film formed on the surface of the refractory immersed in the Al-killed molten steel consists of $\mathrm{Al}_{2} \mathrm{O}_{3}$-rich and high-melting portions and $\mathrm{SiO}_{2}$-rich and low-melting portions. The oxide film formed on the surface of the refractory immersed in the Ti-killed molten steel consists of high-melting portions, mainly composed of $\mathrm{Ti}_{3} \mathrm{O}_{5}$. $\mathrm{SiO}_{2}$ in the oxide film is probably $\mathrm{SiO}_{2}$ remaining unreacted as a result of the direct dissolution of graphite in the surface layer of the refractory.

The following may be said from the above-mentioned results. The oxide film formed on the surface of the refractory immersed in the Al-killed molten steel is present in both liquid and solid phases, nearly covers the surface of the refractory, and prevents the gases diffusing in the bulk of the refractory from transferring to the molten steel. The oxide film formed on the surface of the refractory immersed in the Ti-killed molten steel is present in the solid phase, discontinuously covers the surface of the refractory, and serves as a relatively weak barrier against the transfer of the gases from the refractory to the molten steel. It is thus estimated that the rate of the reaction between the refractory and the molten steel is faster in the Ti-killed molten steel than in the Al-killed molten steel.

\section{Conclusions}

To identify the mechanism controlling the reaction between a silica-containing alumina graphite refractory and low carbon molten steel from the viewpoint of reaction kinetics, the rate of the reaction in the refractory and the rate of the reaction between the refractory and the molten steel were determined by heating and immersion experiments, respectively. The following conclusions were drawn from the comparison of the two sets of reaction rates:

(1) Rate equations for the control of the reaction in the refractory by the diffusion of gases through the pores in the refractory can be applied to the mass loss of the refractory in the heating experiment. An Arrhenius plot of kinetic constants satisfied a linear relation, and the temperature dependence of the Arrhenius plot can be explained by a reaction model for the control of the reaction in the refractory by the diffusion of gases through the pores in the refractory. Therefore, the reaction in the refractory is controlled by the diffusion of the $\mathrm{SiO}$ gas and $\mathrm{CO}$ gas through the pores in the refractory.

(2) In the immersion experiment, an oxide film forms at the refractory-molten steel interface with the result that the $\mathrm{Si}$ content increase in the molten steel is smaller than calculated when the reaction involved is assumed to be controlled by the diffusion of the gases through the pores in the refractory. This is presumably because the rate of reaction between the refractory and the molten steel is controlled by the diffusion of the $\mathrm{SiO}$ gas and $\mathrm{CO}$ gas through the pores of oxide film.

(3) The rate of the reaction between the refractory and the molten steel is faster in the Ti-killed molten steel than in the Al-killed molten steel and exhibits steel grade dependence. This steel grade dependence can be ascribed to the difference in the gas permeability through the oxide film formed at the refractory-molten steel interface between the Al-killed molten steel and the Ti-killed molten steel. In other words, the surface of the refractory immersed in the Al-killed molten steel is nearly covered with a relative dense oxide film present in both solid and 
liquid phases, whereas the surface of the refractory immersed in the Ti-killed molten steel is discontinuously covered with a relative porous oxide film in the solid phase.

\section{REFERENCES}

1) K. Sasai, Y. Mizukami and H. Yamamura: Tetsu-to-Hagané, 79 (1993), 1067.

2) P. D. Miller, J. G. Lee and I. B. Cutler: J. Am. Ceram. Soc., 62 (1979), 147.

3) H. Kyoda, Y. Nanba and N. Tsukamoto: Refractories
(Taikabutu), 36, (1984), 324.

4) Y. Kawai: Reaction Kinetics for Ferrous Metallurgy, Nikkan Kogyo Shimbun, (1978), 94.

5) E. E. Peterson: Chemical Reaction Analysis, Prentice-Hall, (1965), 121.

6) R. B. Bird, W. E. Stewart, and E. N. Lightfoot: Transport Phenomena, John Wiley and Sons, Inc., New York, (1960), 511.

7) Iron and Steel Institute of Japan: Steel Handbook, Vol. I: Fundamentals, Maruzen, Tokyo, (1981), 14.

(Originally published in Tetsu-to-Hagané, 80 (1994), 395 in Japanese) 